\title{
Role of Cardiopulmonary Mechanoreceptors in the Postural Regulation of Renin
}

\author{
RAMIRO A. SANCHEZ, MD, ENRIQUE J. MARCO, MD, CARLOS OLIVERI, MD, \\ FERNANDO J. OTERO, MD, OSVALDO DEGROSSI, MD, LUIS I. MOLEDO, MD, \\ and STEVO JULIUS, MD, ScD
}

To change the stretch on cardiopulmonary mechanoreceptors, large shifts of blood in the capacity space were elicited by tilting and by exerting positive lower body pressure in the tilted position. Twelve volunteers underwent invasive hemodynamic studies and in $\mathbf{1 0}$ other subjects cardiac size was determined by radionuclide cardiography. In all 22 subjects tilting caused the expected increase of renin, which was abolished by lower body compres- sion. Decompression caused renin to increase again. Right atrial pressure in invasive studies and end-systolic and end-diastolic counts in noninvasive studies showed a significant and strong negative correlation with renin and norepinephrine levels. Thus, the degree of stretch of the cardlopulmonary mechanoreceptors is a major determinant of reflex regulation of renin release in humans.

(Am J Cardiol 1987;59:881-886)

$\mathbf{T}$

here is good experimental evidence for the presence of mechanoreceptors in atria, ventricles and pulmonary vessels of animals. ${ }^{1,2}$ Because these stretch receptors are placed in the highly compliant, low-pressure segment of the circulation, they are sensitive to changes in intravascular volume and are primarily involved in control of the extracellular fluid volume.

Expansion of the blood volume increases stretch on cardiopulmonary receptors, which, in turn, through the central nervous system, reduces efferent sympathetic tone, particularly to the kidneys. ${ }^{3}$ This leads to reduction of renal vascular resistance ${ }^{4}$ and suppression of the secretion of renin..$^{5,6}$ Similarly, atrial stretch during volume expansion inhibits secretion of the antidiuretic hormone ${ }^{7}$ and enhances release of the atrial natriuretic factor (ANF) ${ }^{8}$ These factors, then, contribute to the enhanced sodium excretion that accompanies volume expansion. There is, however, some doubt as to whether increased ANF has a physiologic role. ${ }^{9}$

From the Hospital Instituto de Cardiologia, Fundacion Hermenegilda Pombo de Rodreiguez, Academia Nacional de Medicina, Buenos Aires Hospital Aleman, Buenos Aires, Argentina, and the Division of Hypertension, Department of Internal Medicine, University of Michigan Medical Center, Ann Arbor, Michigan. Manuscript received June 26, 1986; revised manuscript received October 23, 1986, accepted October 24, 1986.

Address for reprints: Stevo Julius, MD, ScD, Division of $\mathrm{Hy}-$ pertension, 3918 Taubman Center, University of Michigan Medical Center, Ann Arbor, Michigan 48109-0356.

Whereas a role for cardiopulmonary receptors has been well documented in animals, ${ }^{1-7}$ the functional significance of these receptors in humans is not clear because of the difficulty in devising methods to elicit isolated changes of cardiopulmonary blood volume in humans. However, negative pressure respiration ${ }^{8}$ and total body water immersion ${ }^{9}$ cause a reasonably selective shift of the blood from the peripheral to the central intrathoracic capacitance space, whereas lower body negative pressure ${ }^{10,11}$ and tourniquets around the thighs ${ }^{12}$ decrease cardiopulmonary blood volume. We investigated the influence of cardiopulmonary mechanoreceptors on circulating renin in 22 normal volunteers. We used a technique that permits selective change of the pressure and volume in the intrathoracic capacitance space.

\section{Methods}

Twenty-two normal volunteers ( 5 women, $17 \mathrm{men}$ ), average age $21 \pm 4$ years (range 16 to 26 ), participated in the experiment. To affect changes in the distribution of the blood volume, we used a double-walled suit that resembles fisherman waders and can be filled with water. The suit, originally developed by Julius et al, ${ }^{13}$ when filled with water in upright posture exerts a graded pressure on the lower extremities and lower abdomen and thereby causes translocation of the blood from extremities toward the cardiopulmonary space. 
The whole study lasted 180 minutes and was separated into six 30-minute periods. The first set of measurements was taken after 30 minutes of recumbency (period 1). This was followed by 30 minutes of 45 headup tilt (period 2). Then, the suit was filled with water at 32 to $34^{\circ} \mathrm{C}$ with the subjects remaining tilted for another hour (periods 3 and 4). At that point the suit was evacuated and the subject remained in the tilted position (without compression) for another hour (periods 5 and 6).

Invasive hemodynamic studies were completed in 12 volunteers (group A). The procedure was started at 0800 hours and was finished before noon. A No. $7 \mathrm{Fr}$ Swan-Ganz catheter with a flow-directed thermodilution sensor was threaded through the cephalic vein and appropriately positioned under $\mathrm{x}$-ray monitoring. Cardiac output was determined by the 9520 Evans laboratory cardiac output computer. The measurements at each period represent an average of 3 separate thermodilution injections ${ }^{14}$ into the right atrium at the beginning of each of the 3 consecutive minutes. Right atrial pressure was measured through the thermodilution catheter. The strain gauge (Statham PB50) was placed in recumbency at the midaxillary line of the subject. Upon tilting, the strain gauge was repositioned to be in the same relative position to the heart as in recumbency. The radial artery pressure was measured through a Teflon ${ }^{\otimes}$ catheter. Both cardiac and arterial pressures were recorded continuously on a Hewlett Packard 8890B recorder.
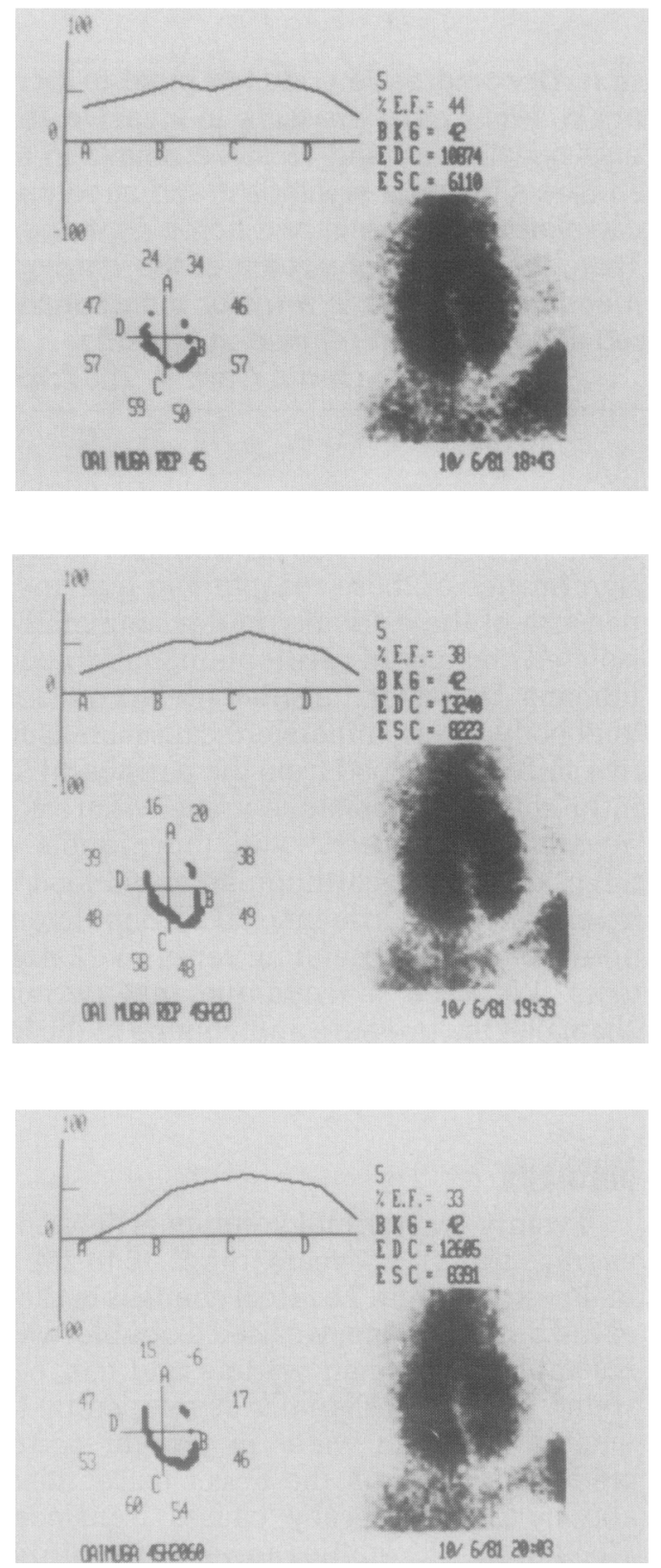

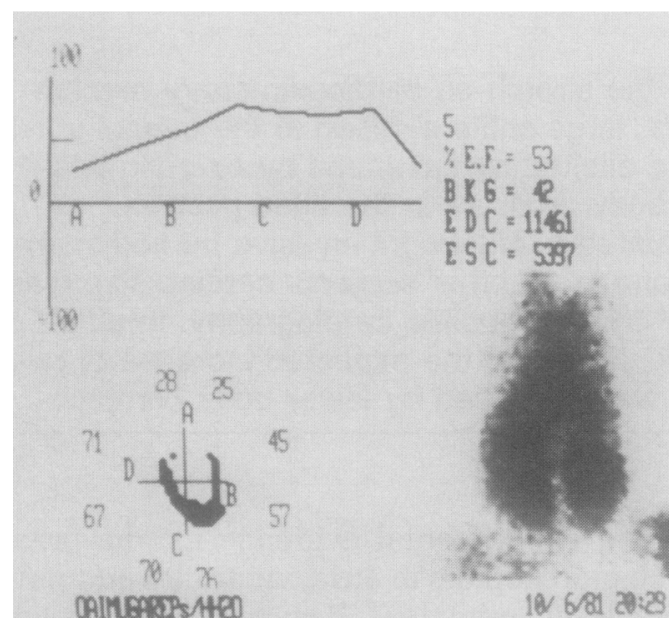

CAILFER:

10. $6812: 28$

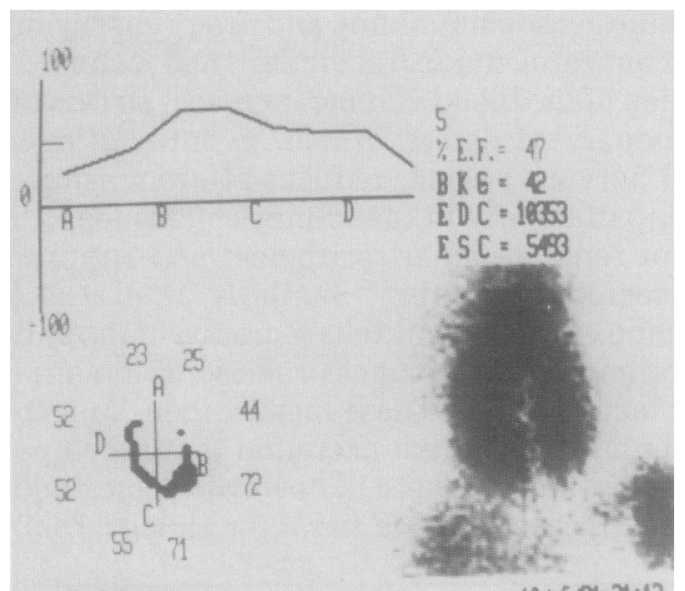

DAI MEA U

FIGURE 1. Representative cardiac Images. Each frame expresses the end-dlastolic radioactivlty during each position studled in the same subject. $A=$ tilt; $B$ and $C=$ tilt with the suit filled ( 30 and 60 minutes); $D$ and $E=$ tilt continued, sult emptled $(30$ and $60 \mathrm{~min}$. utes). BKD $=$ background; EDC $=$ end-diastolic counts; \%E.F. = ejection fraction; ESC $=$ end-systollc counts. 
At the end of each period blood was collected to measure plasma renin activity by radioimmunoassay ${ }^{15}$ and to measure plasma norepinephrine by radioenzymatic assay. ${ }^{16}$ All measurements were done in triplicatc and the results averaged.

Ten volunteers in group B underwent the same basic protocol in regard to observation periods, the positions and filling of the suit, but the blood pressure was measured by sphygmomanometry. In these volunteers we measured the size of cardiac chambers by radioisotope ventriculography (Fig. 1). Five minutes after the beginning of the procedures we injected a radionuclide ( $30 \mathrm{mCi}$ of technetium-99m). In vivo labeling of red blood cells was achieved with intravenous injection of pyrophosphate (10 ng of TCK 14CO) 15 minutes before injection of the radionuclide.

The ventriculogram was recorded at the end of each observation period using a gamma camera (Dynacamera 41561 Picker) with a collimator of low energy and high resolution placed in a modified left anterior oblique position (under 40 to $60^{\circ}$ left rotation and caudal inclination of 15 to $20^{\circ}$ ), which permitted a separation of cardiac chambers. Data were acquired by the multiple-gated electrocardiographically triggered system. Computer-enhanced imaging was achieved through a computer $\mathrm{A}^{2}$ of MDS using $64 \times 64$ byte matrix. Each cardiac cycle was separated into 20 images, accumulating 200,000 counts per image. Values for 300 to 500 cardiac cycles occurring within 5 to 7 minutes were averaged.

Data processing allowed for measurement of global ejection fraction and regional ejection fractions, e.g., separate assessment of the volumes of ventricular chambers. Global ejection fraction was determined by integrating the time-activity curve, expressing changes in the volume as a function of time. The latter value was determined with the use of a locally developed program for the computer $\mathrm{A}^{2}$ of Medical Data Systems, which allowed delineation of borders of left and right ventricles in a semiautomatic fashion. Regional ejection fraction was analyzed by another standard program in the software of the computer. Because measuring changes of the activity over the ventricles could be affected by the counts from the atria, we carefully positioned the collimator to separate the atrial from the ventricular values. However, some contribution of the left atrium to the total count cannot be ruled out. Consequently, only data on the end-systolic and end-diastolic counts of the right ventricle are reported (Fig. 1).

The following conditions had to be met in order to accept radioactive counts per minute as a valid index of cardiac chambers: correct marking of the pool of the blood with technetium- $99 \mathrm{~m}$, acquisition of at least 200,000 cumulative counts per image in all studies, and the relative position between the subject and the collimator had to be constant during the whole experiment. Conditions 1 and 2 have been met for all cases. With respect to condition 3 , a constant relation could be maintained only for periods 2 to 6 , as the relative positions to the collimator changed when the previously recumbent subjects were tilted. Consequently, the val-
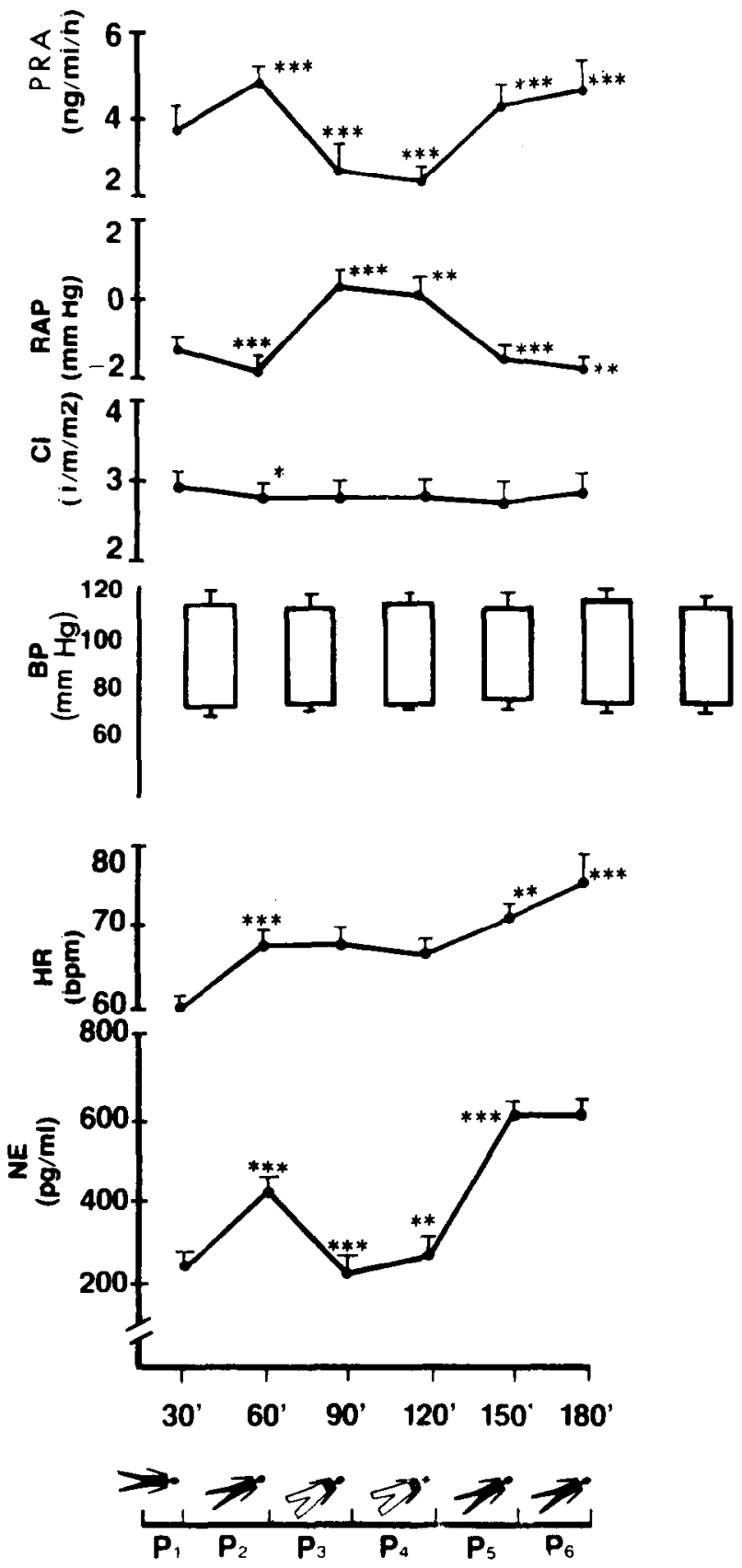

FIGURE 2. Results of Invasive hemodynamic studles in group $A$ ( $n=$ 12). $\mathrm{BP}=$ blood pressure; $\mathrm{Cl}=$ cardiac index; $\mathrm{HR}=$ heart rate; $\mathrm{NE}$ = norepinephrine; PRA = plasma renin activity; RAP = right atrlal pressure.

ues at 60 minutes - the first period of tilt-are given as initial values for subjects in group B.

Values are expressed as mean and standard deviation, using for statistical calculation an analysis of variance with Tukey's criterion for levels of significance.

The studies were approved by the institutional review board and the purpose of them was clearly explained to all subjects. 


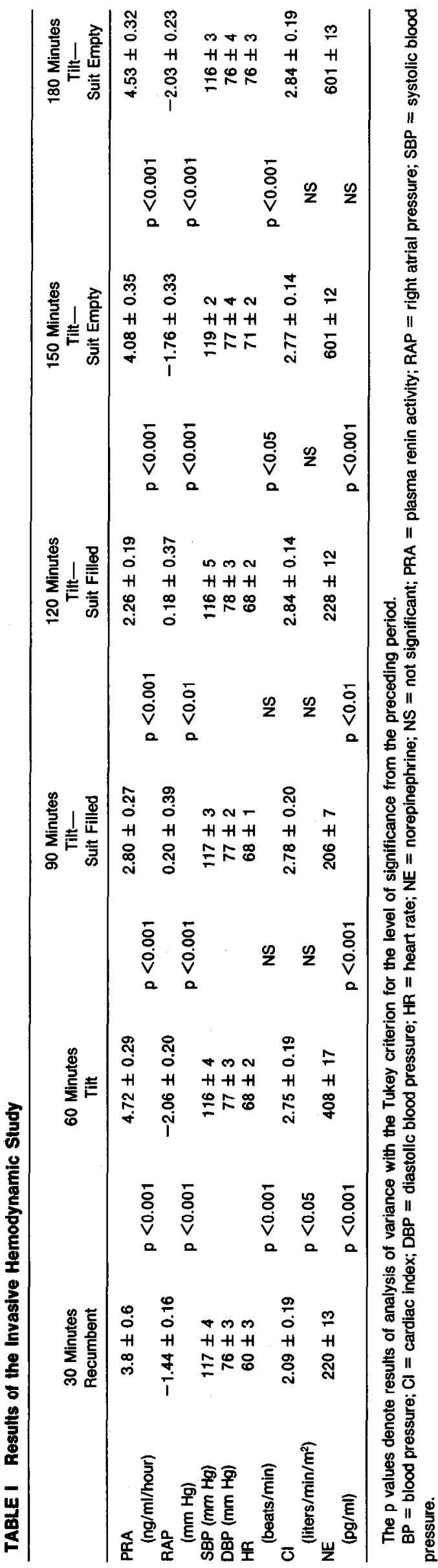

\section{Results}

Group A: Results are given in Figure 2 and Table I. Plasma renin activity increased significantly during tilting ( $\mathrm{p}<0.0001$ ). Filling of the suit in periods 3 and 4 induced a significant decrease of plasma renin activity levels ( $p<0.0001$ ). Draining of the suit in periods 5 and 6 again induced an increase of plasma renin activity to levels similar to the period 2. Right atrial pressure decreased significantly on tilt ( $p<0.0001$ ), increased during filling of the suit (periods 3 and $4, p<0.0001$ ), and decreased again when the suit was drained in periods 5 and 6 . Across all conditions a negative relation existed between plasma renin activity and right atrial pressure (Fig. 3). Plasma norepinephrine values mirrored changes in plasma renin activity: They significantly increased during tilt ( $p<0.0001$ ), were suppressed with filling of the suit in periods 3 and 4 ( $p<0.0001$ ) and increased again after the suit was drained in periods 5 and 6 ( $p<0.0001$ ).

Cardiac index fell slightly only during the first condition of tilt at 60 minutes ( $p<0.05$ ).

Heart rate increased with tilt, was not affected by filling of the water suit and increased further after draining of the suit so that at period 6 it was significantly elevated over period 2 ( $\mathrm{p}<0.0001$ ).

Group B: Table II lists values for the experiments using radioactive ventriculography. Plasma renin activity on tilt was initially high and then were suppressed during filling of the water suit at 90 and 120 minutes, and returned to high levels when the suit was drained.

Compression with the suit caused a significant increase of end-diastolic and end-systolic counts of the right ventricle; upon decompression the counts decreased to values comparable to those at the beginning of tilt (period 2). Similar trends could not be found in regard to left end-systolic or end-diastolic counts. Systolic and diastolic blood pressures and heart rate did not change significantly throughout this procedure. The failure of heart rate to increase in periods 5 and 6 in this group although it increased in group A may be explained by the discomfort of the invasive procedures in group A.

Since right ventricular end-systolic and end-diastolic counts showed wide interindividual variability, we analyzed the relation of the counts to plasma renin activity within persons across the 5 periods of observation (Fig. 4). Negative slopes were achieved for all study participants and the values for the fit were strong in all but 2 instances.

\section{Discussion}

The role of the cardiopulmonary mechanoreceptors in the regulation of renin in humans is controversial. Pooling of the blood in the peripheral veins through lower body negative pressure produces a decrease of right atrial pressure ${ }^{17}$ and cardiac output, ${ }^{18}$ but the reported effects on renin levels are discordant. Fasola and Martz ${ }^{19}$ reported elevation, whereas Mark et $\mathrm{al}^{20}$ failed to observe such a renin response to low degrees of lower body negative suction. With lower body negative suction, the negative pressure is trans- 




FiCURE 3. Relation between right atrlal pressure (RAP) and plasma renin (PRA) activity across 6 periods in study A. Bar represents standard deviation.

mitted throughout the lower abdominal cavity, as evidenced by a lower position of the diaphragm. ${ }^{21}$ This negative pressure probably elicits reflexes from the richly innervated abdominal cavity, ${ }^{22}$ and it is also possible that the transmural renal pressure is altered.

To induce a selective decrease of right atrial pressure without changes in intraabdominal pressure, Kiowski and Julius ${ }^{12}$ used inflatable tourniquets placed over both thighs. Right atrial pressure, cardiopulmonary blood volume and cardiac output decreased and plasma renin activity increased. This increase of plasma renin was believed to be reflexmediated because (1) renin failed to increase in patients with transplanted, and therefore denervated, kidneys; (2) $\beta$ blockade abolished the renin response to thigh cuff inflation; and (3) an increase of plasma nor-
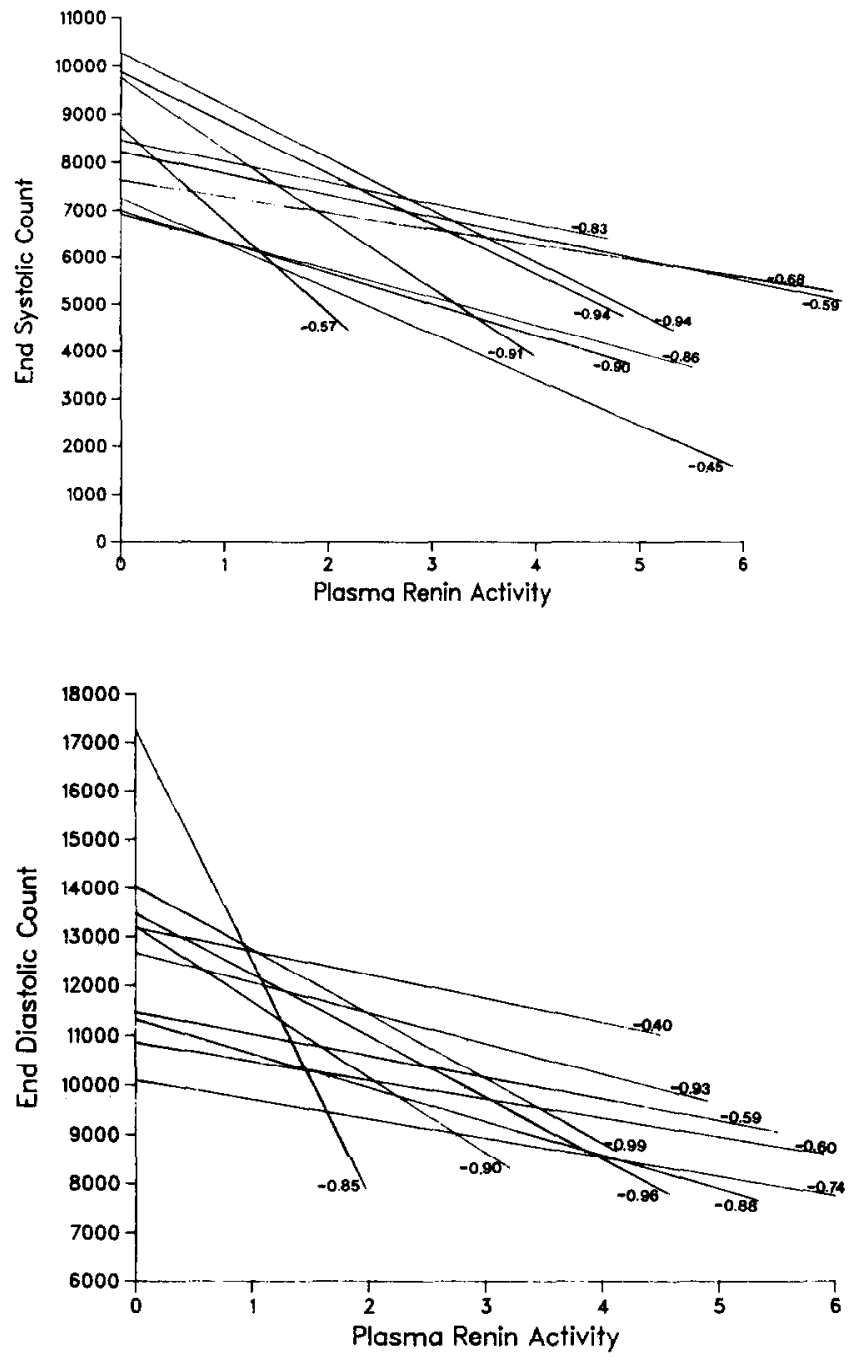

FIGURE 4. Relation between plasma renin activity and end-systollc and end-dlastollc counts. A linear regression was calculated for 5 periods for each subject. Corresponding $r$ values are given for each Individual line.

TABLE II Results of the Radionuclide Imaging Study

\begin{tabular}{|c|c|c|c|c|c|c|c|c|c|}
\hline & $\begin{array}{c}60 \text { Minutes } \\
\text { Tilt }\end{array}$ & & $\begin{array}{l}90 \text { Minutes } \\
\text { Suit Filled }\end{array}$ & & $\begin{array}{l}120 \text { Minutes } \\
\text { Suit Filled }\end{array}$ & & $\begin{array}{l}150 \text { Minutes } \\
\text { Tilt- } \\
\text { Suit Empty }\end{array}$ & & $\begin{array}{l}180 \text { Minutes } \\
\text { Tilt- } \\
\text { Suit Empty }\end{array}$ \\
\hline $\begin{array}{l}\text { PRA } \\
\text { (ng/mi/hour) } \\
\text { EDC (RV) } \\
\text { (cpm) }\end{array}$ & $\begin{array}{c}3.34 \pm 1.39 \\
9,564 \pm 1,115\end{array}$ & $\begin{array}{l}p<0.05 \\
p<0.01\end{array}$ & $\begin{array}{r}1.65 \pm 0.78 \\
11,930 \pm 1,637\end{array}$ & $\begin{array}{l}\text { NS } \\
\text { NS }\end{array}$ & $\begin{array}{c}1.19 \pm 0.59 \\
11,642 \pm 1,419\end{array}$ & $\begin{array}{l}p<0.05 \\
p<0.05\end{array}$ & $\begin{aligned} 2.71 & \pm 1.15 \\
10,038 & \pm 1,501\end{aligned}$ & $\begin{array}{l}\text { NS } \\
\text { NS }\end{array}$ & $\begin{array}{r}3.73 \pm 1.64 \\
-9,130 \pm 879\end{array}$ \\
\hline $\begin{array}{c}\text { ESC (RV) } \\
\text { (cpm) }\end{array}$ & $5,841 \pm 994$ & $p<0.05$ & $7,315 \pm 1,040$ & NS & $7,761 \pm 1,264$ & $p<0.01$ & $6,135 \pm 1,395$ & NS & $5,687 \pm 1,074$ \\
\hline $\begin{array}{c}\text { EDC (LV) } \\
(\mathrm{cpm})\end{array}$ & $8,226 \pm 1,584$ & NS & $8,703 \pm 2,029$ & NS & $8,868 \pm 1,686$ & NS & $8,767 \pm 1,345$ & NS & $8,286 \pm 1,220$ \\
\hline $\begin{array}{c}\mathrm{ESC}(\mathrm{LV}) \\
(\mathrm{cpm})\end{array}$ & $3,357 \pm 886$ & NS & $3,723 \pm 1,721$ & NS & $3,388 \pm 1,000$ & NS & $3,358 \pm 726$ & NS & $3,277 \pm 729$ \\
\hline $\begin{array}{l}\text { SBP } \\
\qquad(\mathrm{mm} \mathrm{Hg})\end{array}$ & $108 \pm 9$ & NS & $113 \pm 7$ & NS & $114 \pm 6$ & NS & $113 \pm 6$ & NS & $114 \pm 8$ \\
\hline $\begin{array}{l}\mathrm{DBP} \\
\quad(\mathrm{mm} \mathrm{Hg})\end{array}$ & & NS & $71 \pm 10$ & NS & $73 \pm 7$ & NS & & NS & $75 \pm 8$ \\
\hline $\begin{array}{l}\text { HR } \\
\text { (beats/min) }\end{array}$ & $68 \pm 3$ & NS & $68 \pm 11$ & NS & $69 \pm 12$ & NS & $69 \pm 12$ & NS & $69 \pm 13$ \\
\hline
\end{tabular}

The $\mathrm{p}$ values denote results of analysis of variance with the Tukey criterion for the level of significance from the preceding period. $E D C=$ end-diastolic counts; $E S C=$ end-systolic counts; $R V=$ right ventricle; $L V=$ left ventricle; other abbreviations as in Table I. 
epinephrine levels accompanied the plasma renin increase. Later, Egan et al ${ }^{13}$ used numerous other maneuvers to separate the effects of the arterial and cardiopulmonary receptors and concluded that the cardiopulmonary receptors have a predominant role in the control of renin release.

Our studies complement the investigations of Julius and co-workers in 2 important ways: They have not carried out offset and onset studies of the effect of increasing the stretch of cardiopulmonary receptors on renin levels and they have not independently assessed the cardiac size during their experiments.

In the present experiments, tilting induced the well known compensatory activation of the renin-angiotensin and sympathetic nervous system to upright posture, which was fully abolished upon filling of the suit with water. Filling and draining of the suit caused significant changes of right atrial pressure (Table I, Fig. 2) and right-heart chamber volumes by ventriculography (Table II). Under all conditions right atrial pressure levels (Fig. 3) and radioactivity counts over the right ventricle (Table II) showed a clear negative correlation to plasma renin activity. We therefore conclude that the major determinants of the renin response to upright posture are the pressures and volumes maintained in the cardiopulmonary capacitance space. The observed parallel changes of renin and norepinephrine levels (Table I and II) support the assumption that this relation is due to reflex release of renin. That the relation is not secondary to hemodynamic changes can be seen in Figure 2.

Filling of the water suit caused significant shifts in cardiopulmonary blood volume, without large effects on cardiac output (Fig. 2). In that regard, our experiments offer a clearer picture than total body water immersion, ${ }^{9}$ which also elicits renin suppression but is associated with very large increases of central venous pressure ${ }^{23}$ and substantial elevation of cardiac output. ${ }^{24}$

The role of ANF should be discussed. Increases in right atrial pressure elicit increases of $A N F{ }^{25} \mathrm{ANF}$ can suppress plasma renin levels in animals. ${ }^{26}$ However, experiments by Goetz et $\mathrm{al}^{27}$ refute that changes in ANF have a physiologic role at least in regard to volume diuresis. Furthermore, previous research strongly indicates that the renin increase that followed the decrease of right atrial pressure is neurogenic because it does not occur in patients with denervated kidneys. ${ }^{12}$ It is difficult to visualize 2 mechanisms, one of a neurogenic increase in renin when right atrial pressure decreases and another humorally mediated renin suppression when right atrial pressure increases. Consequently, we interpreted the renin decrease in our experiments to reflect a direct suppression of sympathetic discharge to the juxtaglomerular cells in the kidney. It remains to be seen whether further research may show also a role of ANF in these circumstances.

\section{References}

1. Linden RJ. Function of cardiac receptors. Circulation 1968;48:463-480. 2. Mancia G, Donald DE. Demonstration that the atria, ventricles and lungs each are responsible for a tonic inhibition of the vasomotor center in the dog. Circ Res 1975;36:310 318.

3. Clement DL, Pelletier CL, Shepherd JT. Role of vagal afferents in the control of renal sympathetic nerve activity in the rabbit. Circ Res 1972;31:824830.

4. Oberg B, Thoren P. Circulatory responses to stimulation of medullated and non-medullated afferents in the cardiac nerve of the cat. Acta Physiol Scand 1973;87:121-132

5. Mancia G, Romero JC, Shepherd JT. Continuous inhibition of renin release in dogs by vagally innervated receptors in the cardiopulmonary region. Circ Res 1975;36:529-535.

6. Thames MD. Reflex suppression of renin release by ventricular receptors with vagal afferents. Am I Physiol 1977;233:H181-H184.

7. De Torrente A, Robertson GL, Mc Donald KM, Schrier RW. Mechanism of diuretic response to increased left atrial pressure in the anesthetized dog. Kidney Int 1975;8:355-361.

8. Siekar HO, Gauer OH, Henry JP. The effect of continuous negative pressure breathing on water and electrolyte excretion by the human kidney. I Clin Invest 1954;33:572-577.

9. Epstein M. Renal effects of head-out water immersion in man: implications for an understanding of volume homeostasis. Physiol Rev 1978;58:529-581. 10. Brown E, Goei JS, Greenfield ADM, Plassaras GC. Circulatory responses to stimulated gravitational shifts of blood in men induced by exposure of the body below the iliac crests to subatmospheric pressure. I Physiol (London) 1966;183:607-627.

11. Wolthuis RA, Hoffler GW, Johnson RL. Lower body negative pressure as an assay technique for orthostatic tolerance. III. A comparison of the individual response to incremental leg negative pressure vs increment lower negative pressure. Aerospace Med 1970;41:1354-1357.

12. Klowsk1 W, Julius $S$. Renin response to stimulation of cardiopulmonary mechanoreceptors in man. I Clin Invest 1978;62:656-663.

13. Egan B, Julius S, Cottier C, Sanchez RA, Julius S. Role of cardiovascular receptors on neural regulation of renin release in normal man. Hypertension 1983;5:779-786

14. Forrester J, Ganz W, Diamond G, McHugh T, Chonette DW, Swan HIC. Thermodilution cardiac output determination with a single flow directed catheter. Am Heart I 1972;83:306-311.

15. Haber E, Koemer T, Page LB, Kliman B, Purnode A. Application of radioimmunoassay for angiotensin I to the physiologic measurements of plasma renin activity in normal human subjects. J Clin Endocrinol 1969;29:13491355.

16. Peuler [D, Johnson GA. Simultaneous single isotope radioenzymatic assay of plasma norepinephrine, epinephrine and dopamine. Life Sci 1977;21:625636.

17. Zoller RP, Mark AL, Abboud FM, Schmid PG, Heistad DD. The role of low pressure baroreccptors in reflex vasoconstrictor responses in man. I Clin Invest 1972;51:2967-2972.

18. Murray RH, Thompson LJ, Bowers JA, Albright CD. Hemodynamic ef fects of graded hypovolemia and vasodepressor syncope induced by lower body negative pressure. Am Heart I 1968;76:799-811.

19. Fasola AF, Martz BL. Peripheral venous renin activity during $70^{\circ}$ tilt and lower body negative pressure. Aerospace Med 1972;43:713-715.

20. Mark A, Abboud F, Fitz AE. Effects of low and high pressure baroreceptors on plasma renin activity in humans. Am I Physiol 1978;235:H29-H33.

21. Millege RD, Musgrave FS, Zechman FW. Radiographic studies of the chest during changes in posture and lower body negative pressure. Radiology 1968;90:674-678.

22. Tuttle RS, McCleary M. Mesenteric baroreceptors. Am I Physiol 1975;229:1514-1519.

23. Arborelius M Jr, Balldin UI, Lilia B, Lundgren CEG. Hemodynamic changes in man during immersion with the head above water. Aerospace Med 1972;43:592-598.

24. Begin R, Epstein M, Sackner MA, Levinson R, Dougherty R, Duncan D. Effects of water immersion to the neck on pulmonary circulation and tissue volume in man. I Appl Physiol 1976;40:293-299.

25. Bates ER, Schenker Y, Grekin R. Relationship of hemodynamic parameters to plasma level of immunoreactive atrial natriuretic hormone in man. Circulation 1986;73:1155-1161.

26. Ledsome IR, Wilson N, Courneya CA, Rankin AJ. Release of atrial natriuretic peptide by atrial distension. Can I Physiol Pharmacol 1985;63:739742.

27. Goetz KL, Wang BC, Geer PG, Leadley RJ, Jr, Reinhardt HW. Atrial stretch increases sodium excretion independently of release of atrial peptides. Am J Physiol 1986;250:R946-R950. 